\title{
Ozone therapy as complementary treatment for surgical infection:
} case report.

\author{
Josip Buric ${ }^{1}$, Marco Damilano², Pedro Berjano² \\ ${ }^{1}$ Villa Torri Hospital GVM ${ }^{2}$ IRCCS Istituto Ortopedico Galeazzi
}

\section{Әे OPEN ACCESS}

\section{Citation}

Buric J, Damilano M, Berjano P, Ozone therapy as complementary treatment

for surgical infection: case report. $J$ Ozone Ther. 2020:4(5)

doi: 10.7203/jo3t.4.5.2020.18022

\section{Academic Editor \\ Jose Baeza-Noci, \\ School of Medicine, Valencia \\ University, SPAIN}

\section{Editor}

World Federation of Ozone Therapy,

Brescia, ITALY

\section{Received}

April 20, 2019

Accepted

July 20, 2019

\section{Published}

December 15, 2020

\section{Intellectual Property}

Martin Grangeat A.

This is an open access article distributed under the terms of the Creative Commons Attribution License (CC BY 4.0), which permits unrestricted use, distribution, and reproduction in any medium, provided the original author and source are credited.

\section{Authors information \\ joburic77@gmail.com}

\section{ABSTRACT}

Background: Infection is a serious surgical complication that increases significantly morbidity and mortality rates as well as health care expenses. Bacterial evergrowing resistance to antibiotics makes the treatment of such events even more troublesome.

Objective: Report on a surgical infection case treated with ozone as a complementary therapy

Case presentation: Female, 65 years old, submitted to a complex surgical procedure for adult kyphotic deformity correction that presented with early postsurgical infection. The patient was treated with revision surgery and antibiotics that improved the condition but were unable to eliminate the infection. Ozone, in its gaseous form, was injected subcutaneously and paravertebrally twice a week for three weeks. After 3 weeks of treatment the wound healed completely and repeated visits and blood exams up to one year after the surgery did not show recurrence of infection

Discussion and Conclusions: Although we cannot recommend the extended use of ozone therapy for surgical infections, the results of this case report indicate a new way that merits to be explored.

\section{Introduction}

Infection is one of the most fearsome complications in spinal surgery and has the ability to transform even a simple procedure in a nightmare situation with high postoperative morbidity, mortality and important increase in health care expenses. (1) Literature reports this event to range between $0.5 \%$ and $18.8 \%$. $(2,3)$ This extremely wide range can bejustified by the incidence of infection occurring in different spinal surgery procedures. More complex procedures, such as deformity corrections and long posterior instrumentations, bear a higher risk of infection while low complexity procedures such as microscopically assisted ones, will have low or very low infection rate. $(4,5)$

Surgical infections have three possible sources. External, environmental source, originating from surgical instruments orthe theater air,an external, biological source, taking place from the skin near the incision site and an internal source, arising from internal mucous membranes such as gastro-intestinal, genitourinary or oro-pharingeal sites of endogenous, usually chronic, infections. In order to become clinically evident, the infection requires a sufficient bacterial load, a sufficient tissue damage and a significant lowering of immune response of the host. $(6,7)$ The most frequent pathogens giving rise to infections are the aerobic ones, however, anaerobic microorganisms were found responsible for infections in approximately $38 \%$ of cases. The scarce information on these last ones is a 
consequence of a more difficult and cost-consuming procedureto verify them. $(4,6)$ Indeed, it seems that the combined action of aerobic and anaerobic pathogens is frequently involved in the occurrence of the surgical infection (8)

Risk factors such as obesity, diabetes, age over 60 , chronic infections, prolonged operating time, blood loss, post-operative pain, anxiety, depression, etc., has been recognized as significant risk factors increasing the incidence of infection after spinal surgery $(9,10)$. Up to date, there is no univocal idea on mechanisms of infection development. One theory favorsthe infection as a direct mechanical effect of bacterial virulence.Others are more incline to indicate the type of bacteria as being responsible for infection initiation. $(11,12,13)$

Ozone is a triatomic allotrope of oxygen with a high electro-voltaic potential. Its known bactericidal, fungicidal and viristatic action is largely used in food and drinking water industry $(14,15)$. The mechanism through which it explicatesthe bactericidal action is believed to lay in its capacity to destroy the protein and lipid reactive sites on cell membranes of bacteria. (16) Laboratory findings indicate ozone to have a high destructive potential on vegetative and planktonic forms of bacteria immersed in water and/or saline solution. (17) Results on its activity on biofilms are not so univocal however, ozone seems to have better destruction capacity then common treatment with antibiotics $(18,19,20,21,22,23,24)$ Toxicological tests found that ozone, as applied to laboratory animals in acute and subacute doses, didn't show any tissue damage when studied either under electronic microscopy or histology. (25)

We report a case of post-operative spine surgery infection treated successfully with intra-wound application of gaseous form of ozone.

\section{Case presentation}

Female, 65 years of age, presented to the outpatient clinic due to progressively worsening low back pain started three years before with recent radiation of pain to both her lower extremities mainly to the right side. Radiological examination showed a case of spinal stenosis at L3/L4 and L4/L5 levels with significant sagittal

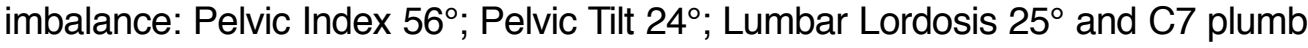
line +115 millimeters. (Figure 1\&2)

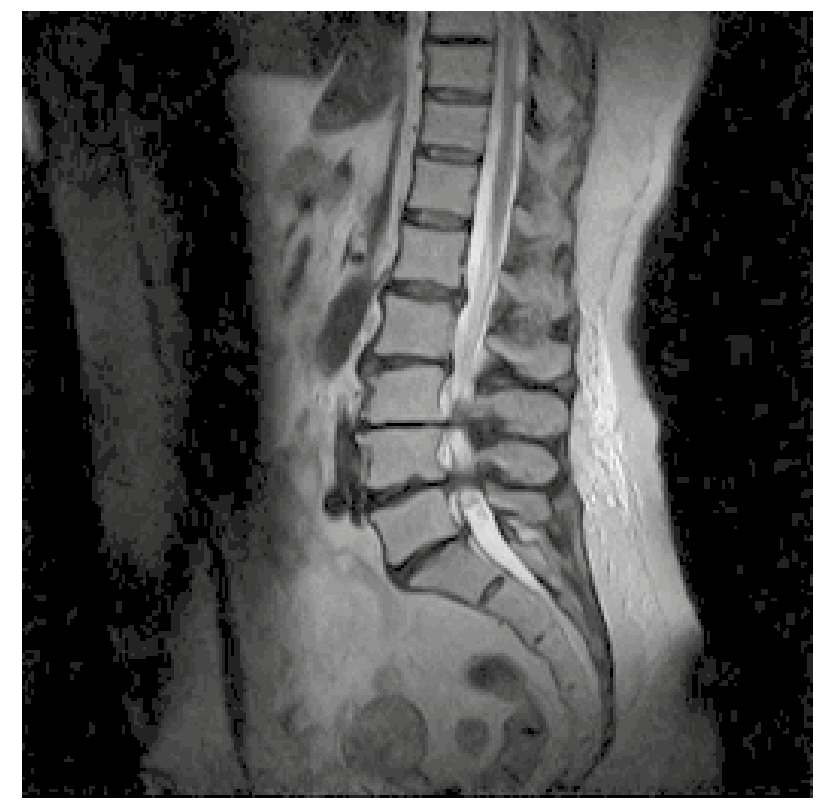

Figure 1 


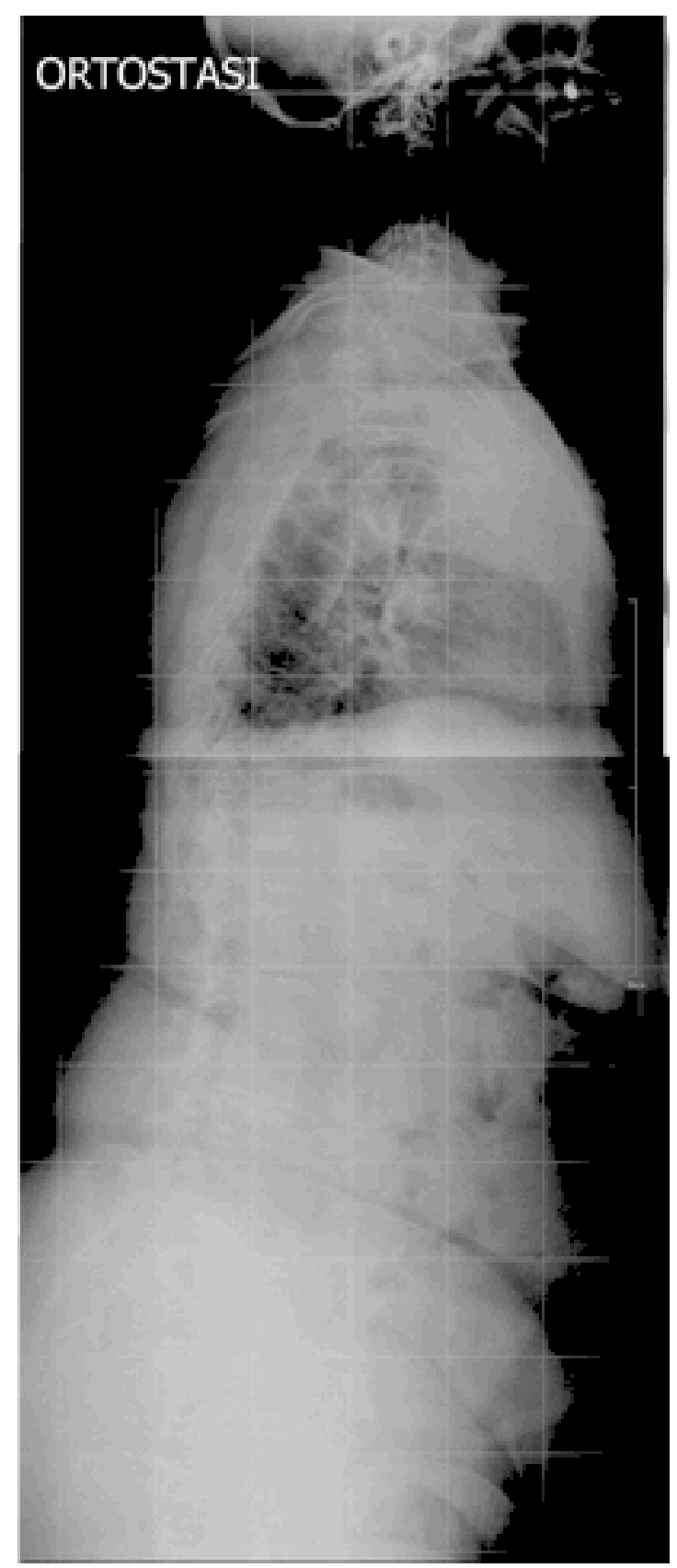

Figure 2

The patient's BMI was 33.06 and the bone densitometry showed a T score of -0.6. No significant comorbidities or risk factors were reported. The patient was submitted to a complex spinal surgical procedure for sagittal imbalance correction and decompression. An anterior approach at L5/S1 was donewith an ALIF (anterior lumbar interbody fusion) cage insertion and upon, the patient was turned laterally and an ACR XLIF (anterior column release extreme lateral interbody fusion) cage was positioned in L3/L4 obtaining an approximately 30 degrees of sagittal correction. Moreover, from the same lateral approach another two lordotic XLIF cages were positioned at L4/L5 and L2/L3 levels for further improvement of the balance and anterior support to the spine. 
Upon, the patient was positioned prone on the Risser frame, and a decompression of the lumbar spine with pedicle screw instrumentation from the ileum up to L1 was done. (Figure 3)

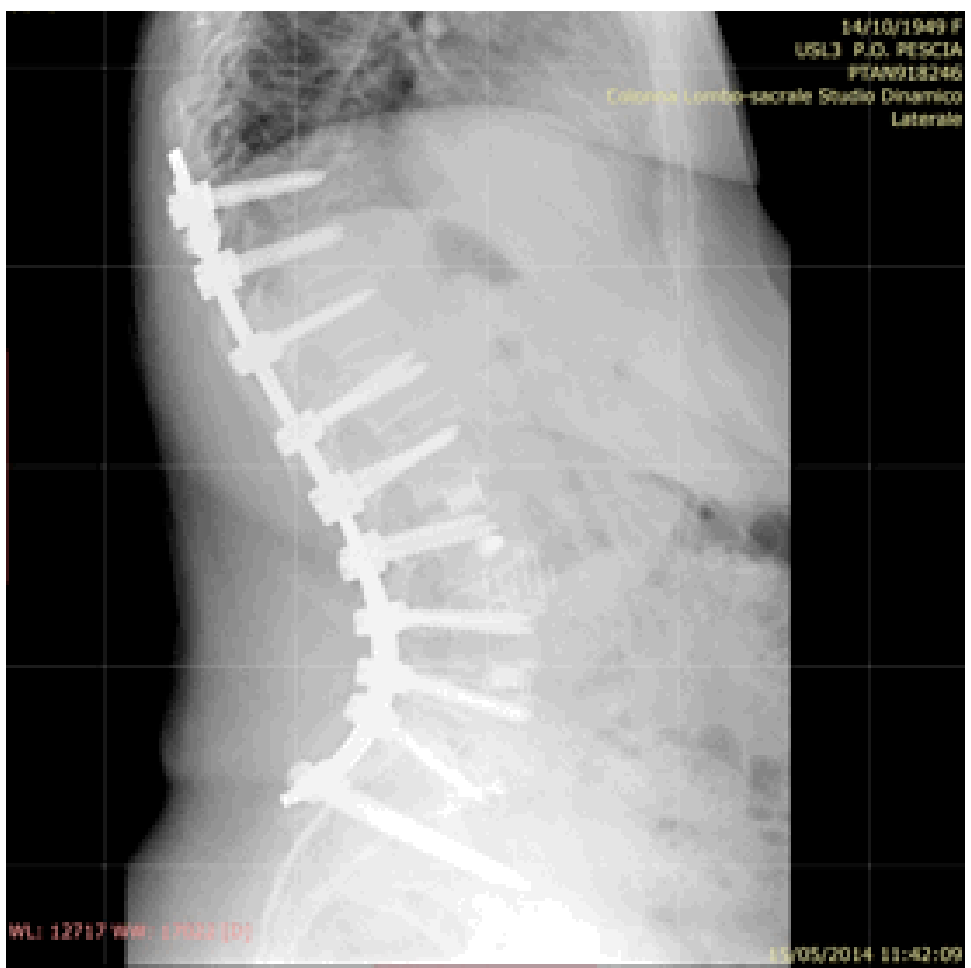

Figure 3

On 5th post-op day the patient presented with hyperthermia $\left(39.1^{\circ} \mathrm{C}\right)$ and wound discharge. The day after, blood culture was taken and the resultshowed positivity for Enterococusfaecalis. C-Protein reactivity (CPR) showed values of 16.59. The MRI (magnetic resonance imaging) showed diffuse inflammatory changes of the paravertebral muscles and localized collections. (Figure 4 \& 5).
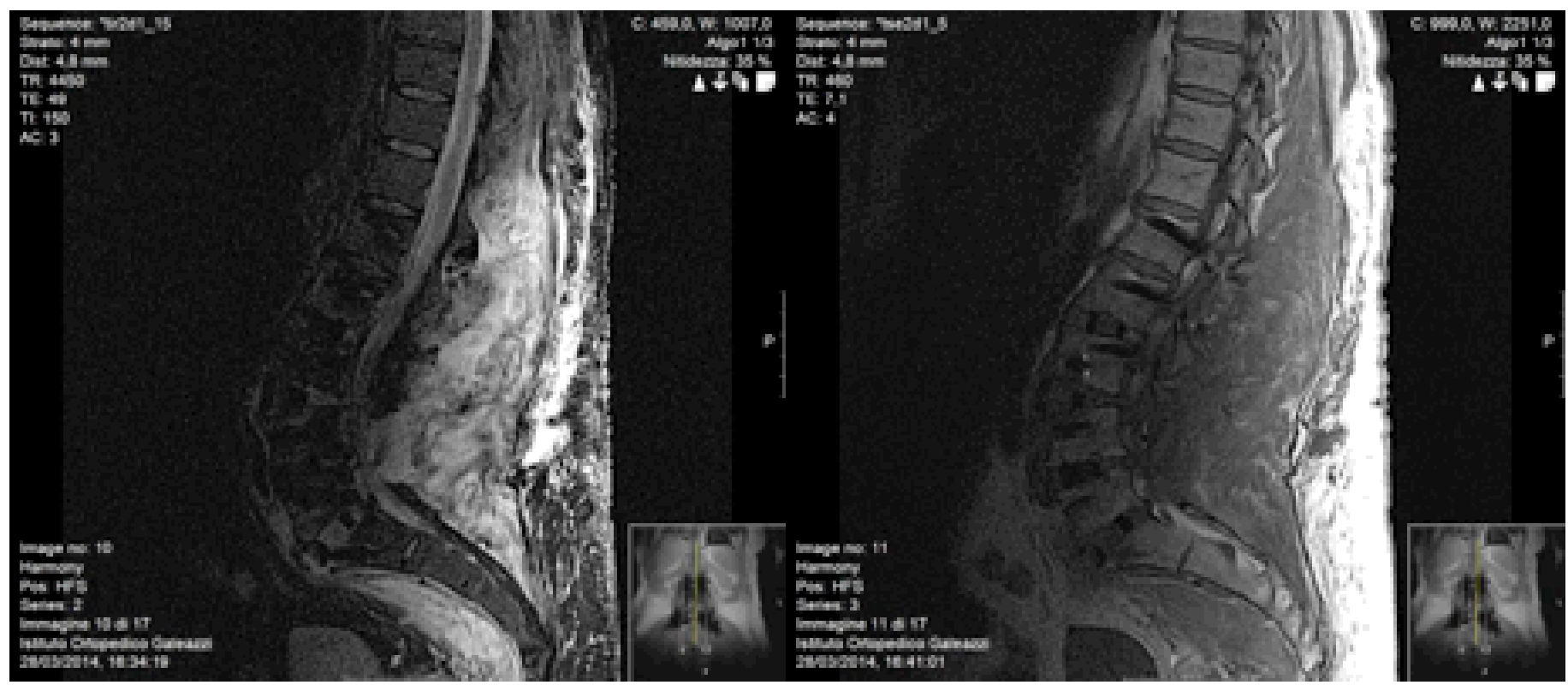

Figure 4 \& 5 
Due to aforementioned findings, arevision surgery with debridement was done. During the surgery, loosening of the upper screws was found and an extension of the instrumentation up to D10 was performed. Multiple tissue swabs taken during the surgery confirmed the results of blood culture test. The infectious disease specialist advised the following treatment:Ampicilin $3 g r \times 4$ a day and Gentamicin $320 \mathrm{mg}$ a day. After 15 days, and significant improvement in health conditions, the medication was changed to Augmentin $1 \mathrm{gr} \times 3$ a day. On discharge from the hospital, the patient's blood values showed significant reduction of inflammatory markers: White Blood Cells 4.79 and CPR 3.28.

Upon discharge the patient continued with the antibiotic treatment and was followed closely with weekly out-patient visits. The surgical wound healing was not optimal with two wound fistulas still discharging yellowish, dense, liquid. The wound continued to show redness and tenderness. After almost a month from the discharge the CPR values were almost the same (3.5) as it was the wound drainage.The patient started showing severe tiredness, loss of appetite and general health deterioration. Before proceeding with a new revision surgery, a decision was taken to try using ozone therapy for its known bactericidal effects. Oxygen-ozone mixture in gaseous form was injected inside the wound with the following modality:

The procedure was done in outpatient clinic with the patient laying in lateral decubitus. Needle cannula of $16 \mathrm{G}$ was inserted inside the fistula and the syringe suction was applied as to remove the subcutaneous liquid collection.Approximately 120 milliliters $(\mathrm{ml})$ o yellowish and dense liquid was removed. Then, using a 60 $\mathrm{ml}$ syringe, ozone-oxygen mixture in concentration of 20 micrograms of ozone / milliliter of oxygen, was injected into the subcutaneous space. Eight syringes of gas mixture were applied for a total of $480 \mathrm{ml}$. Then another two, $60 \mathrm{ml}$ injections, were introduced deep inside the paravertebral muscles using a $20 \mathrm{G}, 5$ centimeter-long, needles. These procedure was repeated twice weekly for two weeks and then again once on the third week. Already from the second week (third treatment), the wound presented in significantly better conditions. The fistulas were still open but the secretion,still yellowish, was not anymore dense. There was no more redness of the wound and the back pain diminished significantly. On the last session the patient presented in much better general health conditions with significantly less pain and tiredness as compared to the first session. The previously described fistulas were completely closed so we had to puncture the skin for the last session. No more discharge could be found even on suction. The skin around the wound was flat and no redness could be seen anymore. The patient repeated her blood exams for inflammatory markers a week after the last session that showed normal values (CPR 1, Pro-calcitonin < 0.5).

During the follow up of up to a year after surgery, the patient was seen once a month and repeated blood exams, initially once a month for two months and then upon on 6 and 12 months were done. No clinical or laboratory signs of infection presented ever more.

\section{Discussion and Conclusion}

Due to the rise of multi-resistant bacteria and a decrease of effectiveness of antibiotics, infections are becoming a serious concern in the health care profession. $(26,27)$. Ozone is being widely used for the treatment of different medical conditions among which the treatment of bacterial, viral and fungal infections. (28) This case illustrates a severe post-surgical infection treated initially with,evidence based, treatment modalities of revision surgery and prolonged regime of antibiotics. Nonetheless, only partial healing was obtained. Adding the ozone into the treatment took over the "status quo" situation and switched the patient on the 
healing side of the process.

Experimental work of different authors indicate that ozone is a highly active bactericidal substance in vitro both on vegetative as well as planktonic forms of bacteria. Seemingly, it also shows superior results in the treatment of biofilms as compared to antibiotics. $(17,19,20,21,22,23,24)$. Ozone therapy for infections seems to have similarities with hyperbaric oxygen treatment. Animal studies comparing these two modalities in acute pancreas infection showed positive result for both treatments with clear prevalence for the ozone therapy. (29)Literature review found a few published articles on the use of ozone for the prevention and treatment of surgical infections in clinical settings. $(30,31)$ The authors state that ozone treatment of the infections showed promising results and indicated ozone having a possible role in prevention of surgical infections, too.

Of course, a single case is not a proven demonstration of clinical benefit, however, it indicates a new complementary treatment modality of the aforementioned condition that should be explored, particularly in the era of ever growing bacterial resistance to antibiotics.

\section{Literature}

1. Calderone RR, Garland DE, Capen DA, Oster H (1996) Cost of medical care for postoperative spinal infections. OrthopClin North Am 27:171-182

2. Olsen MA, Mayfield J, Lauryssen C, Polish LB, Jones M, Vest J, Fraser VJ (2003) Risk factors for surgical site infection in spinal surgery. J Neurosurg 98:14955

3. Pull terGunne AF, van Laarhoven CJHM, Cohen DB (2010) Incidence of surgical site infection following adult spinal deformity surgery: an analysis of patient risk. Eur Spine J 19:982-988

4. Picada R, Winter RB, Lonstein JE, Denis F, Pinto MR, Smith MD (2000) Postoperative deep wound infection in adults afterposterior lumbosacral spine fusion with instrumentation: incidence and management. J Spinal Disord13:42-5 5. Gaynes RP, Culver DH, Horan TC, Edwards JR, Richards C, Tolson JS (2001) Surgical site infection (SSI) rates in the United States, 1992-1998: the National Nosocomial Infections Surveillance System basic SSI risk index. Clin Infect Dis 33:S69-77

6. Bowler PG, Deurden BI, Armstrong DG (2001) Wound microbiology and associated approaches to wound management. CliMicrobiol Rev 14(2):244-269

7. Raahave D, Friis-Moller A, Bjerre-Jespen K, Thiis-Knudsen J, Rasmussen LB (1986) The infective dose of aerobic and anaerobic bacteria in postoperative wound sepsis. Arch Surg 121:924-929

8. Duerden BI (1994) Virulence factors in anaerobes. Clin Infect Dis 18:S253S259

9. Fang A, Hu SS, Endres N, Bradford DS (2005) Risk Factors for Infection After Spinal Surgery. Spine 30(12):1460-1465

10. Olsen MA, Nepple JJ, Riew KD, Lenke L, Bridwell KH, Mayfield J, Fraser VJ (2008) Risk factors for surgical site infection following orthopaedic spinal operations. The Journal of Bone and Joint Surgery 90(1):62-69

11. Saleh K, Sonesson A, Persson B, Riesbeck K, Schmidtchen A (2011) A descriptive study of bacterial load of full-thickness surgical wounds in dermatologic surgery. DermatolSurg37(7):1014-22

12. Turtiainen J, Hakala T, Hakkarainen T, Karhukorpi J (2014) The Impact of Surgical Wound Bacterial Colonization on the Incidence of Surgical Site Infection After Lower Limb Vascular Surgery: A Prospective Observational Study. European Journal of Vascular and Endovascular Surgery 47(4):411-417 
13. Lineaweaver WC, Jacob S, Yan H, Zhang F (2011)Wound cultures as predictors of complications in reconstructive flap procedures. Ann PlastSurg 66(5):572-4

14. Bermond CV (1998) A Review paper: The use of ozone and associated oxidation processes in drinking water treatment. Wat Res 32(11):3208-3222

15. Guzel-seydim ZB, Greene AK, Seydim AC (2004) Use of ozone in the food industry. LWT-Food Science and Technology 34(49):453-460

16. Shinriki N (1994) Mechanism with Ozone. REPORTS OF HOKKAIDO NATIONAL INDUSTRAL RESEARCH INSTITUTE. 61:15-36

17. Hems RS, Gulabivala K, Ng Y-L, Ready D, Spratt DA (2005) An in vitro evaluation of the ability of ozone to kill a strain of Enterococcus faecalis. Int Endodontic Journal 38:22-29

18. Marrie TJ, Costerton JW (1985) Mode of growth of bacterial pathogens in chronic polymicrobial human osteomyelitis. J Clin Microbiology 22:924-933

19. Huth KC, Quirling M, Maier S, Kamereck K, Alkhayer M, Paschos E, Welsch U, Miethke T, Brand K, Hickel R(2009)Effectiveness of ozone against endodontopathogenic microorganisms in a root canal biofilm model. IntEndod $\mathrm{J}$ 42(1):3-13

20. Al-Saadi H, Potapova I, Rochford ET, Moriarty TF, Messmer P (2015) Ozonated saline shows activity against planktonic and biofilm growing Staphylococcus aureus in vitro: a potential irrigant for infected wounds. Int Wound JJan 14

21. Bialoszewski D, Pietruczuk-Padzik A, Kalicinska A, Bocian E, Czajkowska M, Bukowska B, Tyski S (2011) Activity of ozonated water and ozone against Staphylococcus aureus and Pseudomonas aeruginosa biofilms. Medical Science Monitor: International Medical Journal of Experimental and Clinical Research 17(11):BR339-344

22. Koyama R, Okuda K-I, Kazuhiko M, Monroe B, Yoshimitsu M (2015) Antimicrobial and Antibiofilm Effects of Ozonated Water for Prevention and Treatment of Bone and Joint Infections. Journal of St. Marianna University 6(1):17

23. Tachikawa M, Tezuka M, Yamanaka K, Nakamuro K (2006) Studies on the evaluation of disinfections and removal of biofilms by ozone water using a microbial model system. Bull Med \&Hyg Ozone Res, Japan 13:50-56

24. Broadwater WT, Hoehn RC, King PH (1973) Sensitivity of three selected bacterial species to ozone. Applied Microbiology 26:391-393

25. Hoshi S, Sakura M, Kitagawa S, Mori K, Saitou A, Akabori Y, Murakami A (1995) Toxicity Study of Ozonized Water. Journal of Shizuoka Saisei Medicine 12: 89-95

26. Ventola C (2015) The Antibiotic Resistance Crisis Part 1: Causes and Threats. P T. 40(4):77-283

27. Harold CN (1992) The Crisis in Antibiotic Resistance. Science 257:1064-1073 28. Elvis AM, Ekta JS (2011) Ozone therapy: A clinical review. J Nat SciBiol Med 2(1):66-70

29. Bulent U, Mehmet $Y$, Nail E, Omer C, Abdullah K, Tuncer C, Bulent K, Sukru O, Ahmet K, Ahmet G (2010) Efficacy of Hyperbaric Oxygen Therapy and Medical Ozone Therapy in Experimental Acute Necrotizing Pancreatitis. Pancreas 39:9-15 30. Białoszewski D (2003) The use of the intraooperative ozone - theraphy as prophylaxis of infections in surgery of locomotor system with special regard to total hip plasty - a preliminary study. OrtopTraumatolRehabil 30;5(6):781-786

31. Białoszewski D, Kowalewski M (2003) Superficially, longer, intermittent ozone theraphy in the treatment of the chronic, infected wounds. OrtopTraumatolRehabil 30;5(5):652-658 